\title{
Violence against women in intimate relationships
}

Robert Jonzon

Master of Public Health

MPH 2006:27

Nordic School of Public Health 
Violence against women in intimate relationships.

(c) Nordic School of Public Health

ISSN 1104-5701

ISBN 91-7997-161-X 


\section{Master of Public Health}

\begin{tabular}{|c|c|c|c|c|}
\hline \multicolumn{5}{|c|}{ ' } \\
\hline \multicolumn{5}{|c|}{$\begin{array}{l}\text { Title and subtitle of the essay } \\
\text { Violence against women in intimate relationships: } \\
\text { Explanations and suggestions for interventions as perceived by health care workers, local } \\
\text { leaders and trusted community members in a northern district in Vietnam. }\end{array}$} \\
\hline \multicolumn{5}{|c|}{$\begin{array}{l}\text { Author } \\
\text { Robert Jonzon }\end{array}$} \\
\hline \multicolumn{5}{|c|}{$\begin{array}{l}\text { Author's position and address } \\
\text { Senior administrative officer } \\
\text { The National Board of Health and Welfare } \\
\text { SE-106 } 30 \text { Stockholm } \\
\text { Sweden }\end{array}$} \\
\hline \multicolumn{2}{|c|}{$\begin{array}{l}\text { Date of approval } \\
\text { November 30, } 2006\end{array}$} & $\begin{array}{l}\text { Supervis } \\
\text { Profes } \\
\text { Associ }\end{array}$ & $\begin{array}{l}\text { HV/External } \\
\text { Karin Ringst } \\
\text { professor Gl }\end{array}$ & $\begin{array}{l}\mathrm{HV}) \\
\text { rantz (External) }\end{array}$ \\
\hline $\begin{array}{l}\text { No of pages } \\
56\end{array}$ & $\begin{array}{l}\text { Language - essay } \\
\text { English }\end{array}$ & $\begin{array}{l}\text { Language - abstract } \\
\text { English }\end{array}$ & \begin{tabular}{|l|} 
ISSN-no \\
$1104-5701$
\end{tabular} & \begin{tabular}{|l} 
ISBN-no \\
91-7997-161-X
\end{tabular} \\
\hline
\end{tabular}

\section{Abstract}

Objectives: The objectives of the study was to describe how people who face partner violence against women, either as volunteers or as professionals in their everyday work, explain violence against women in intimate relationships and their suggestions for preventive activities.

Methods: Twenty men and twenty women were strategically selected for five focus-group discussions. The interviews were analysed following the procedure for qualitative thematic content analysis.

Findings: The study shows that the participants acknowledged violence against women as a multifaceted phenomenon grounded in the interplay between individual, family-related factors and local community and socio-cultural factors. Men's level of education, 'social evils', women challenging gender role expectations and women's extensive work load were discussed as factors at individual and family level. Poverty in the local community and 'feudal ideologies' were referred to as explanatory factors at structural level. The informants suggested two main ways of preventing violence against women; improved gender equality through information, education and communication, and enforcing policies and law. Examples pertaining to different levels of society were given.

Conclusions: This study shows that behind all of the explanations to intimate partner violence laid the culturally constructed messages about the proper roles of men and women mirroring gender inequality and women's power disadvantage. A hesitation to intervene was found among some of the informants, the medical doctors, while all the others were eager to discuss activities but mainly those they were already undertaking and it seems the local level require further support to better handle this problem.

Key words

intimate partner violence, domestic violence, women's health, focus-group discussions, content analysis, Vietnam. 


\section{CONTENTS}

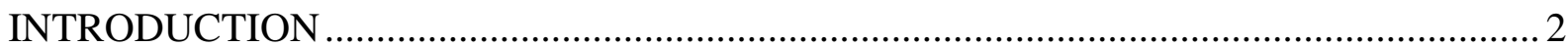

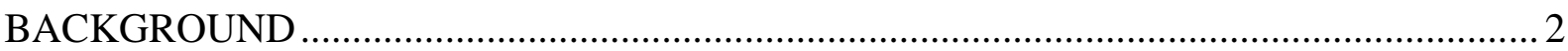

Intimate partner violence, a global Public Health Issue ........................................... 2

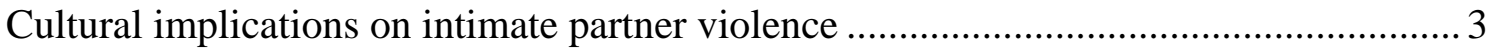

Intimate partner violence, a global Human Rights Issue .............................................. 5

Women's Human Rights in International Law ........................................................... 5

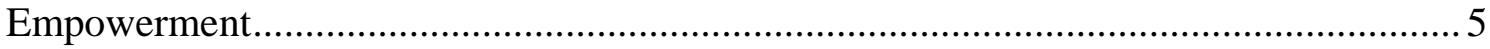

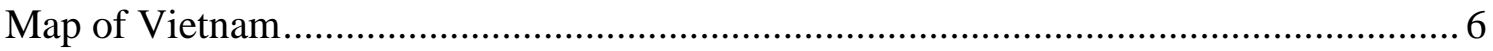

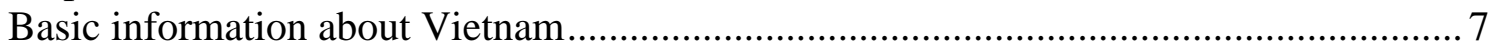

Intimate partner violence in the Vietnamese context ............................................... 8

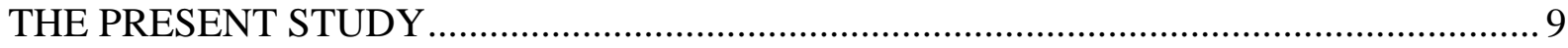

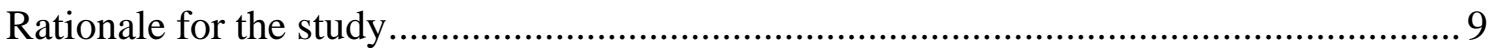

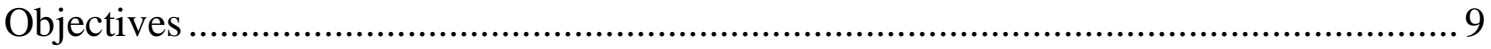

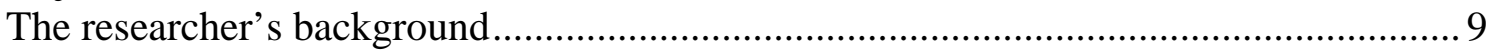

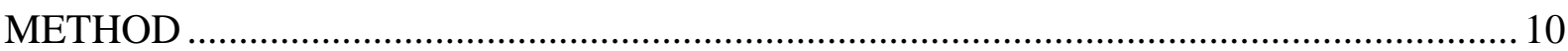

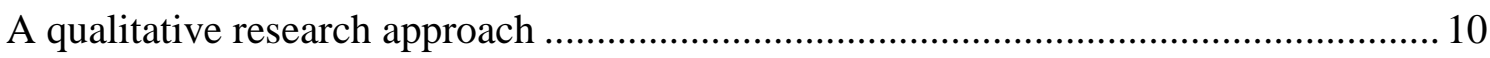

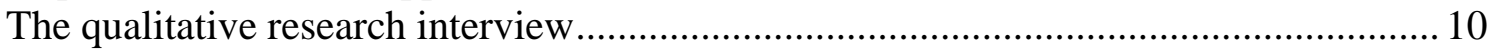

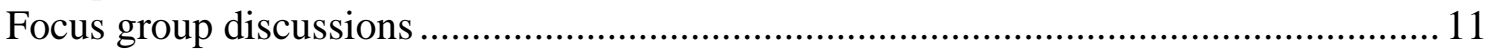

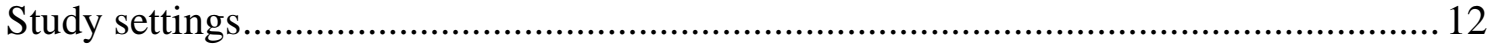

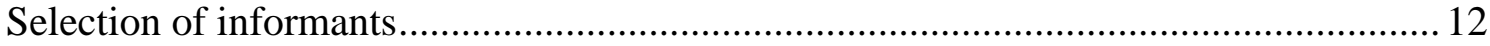

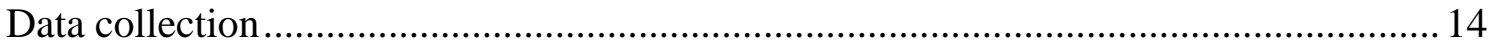

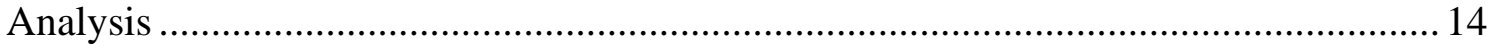

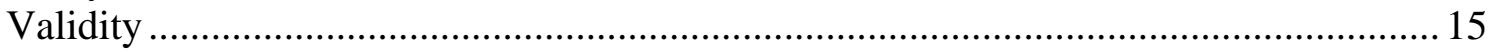

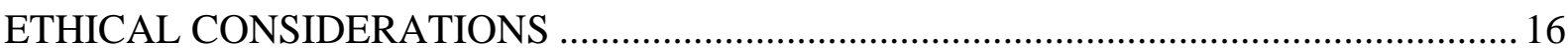

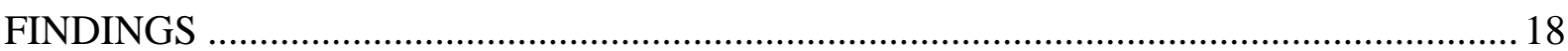

I. Explanations of violence against women in intimate relationship.............................. 18

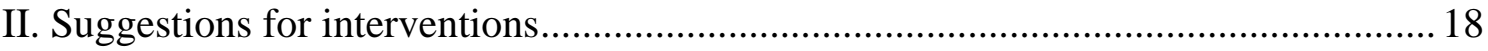

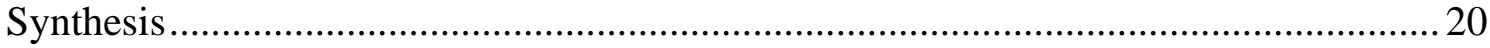

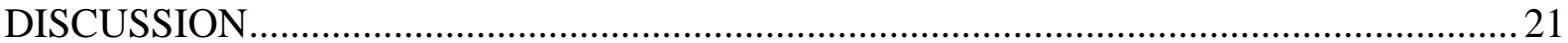

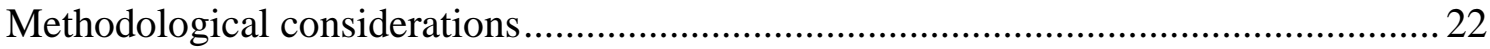

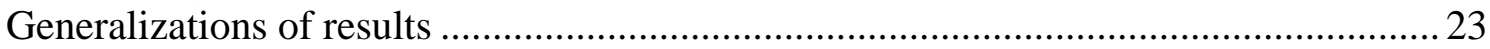

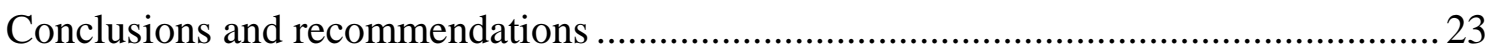

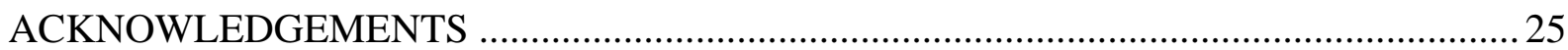

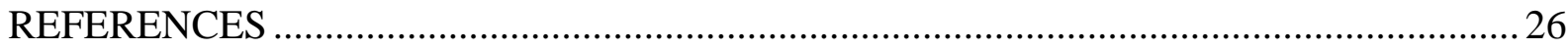




\section{INTRODUCTION}

This study forms part of a larger project on violence against women in northern rural Vietnam. The present study was conducted within the framework of the demographic surveillance site in Bavi District, Ha Tay Province, in northern rural Vietnam.

The study is based on focus group interviews in which men and women participated. Part of the collected data has already been published [1] while the remaining data is presented in this essay and in the attached paper.

The aim of this study was to describe how people who face partner violence against women, either as volunteers or as professionals in their everyday work, explain violence against women in intimate relationships and their suggestions for preventive activities. The overall objective of the study was to contribute to increased knowledge and awareness of violence against women in intimate relationships and thus hopefully influence towards a reduction of such violence in Vietnam and elsewhere.

My interest in public health issues developed during the 1980's when I spent almost six years as a development worker in urban and rural Nepal. During those years I was engaged in various health related projects, though my professional background as a nurse-anaesthetist made the operating room to be my main working place. It was there, in the operating room in the Himalayas I for the first time had to face the consequences of men's physical violence to their own spouses. The severe burn cases, open wounds and fractures were taken care of in the emergency room and in the operating theatre but I still wonder who took care of the accompanied mental scars that these women most likely also suffered from.

\section{BACKGROUND}

\section{Intimate partner violence, a global Public Health Issue}

Intimate partner violence (IPV) is the kind of violence that occurs in the private sphere between people related through kinship, intimacy or law [2]. It refers to the abuse that usually takes place between husband and wife, or present or former partner. The overwhelming burden of partner violence is shouldered by women, although men also have to face violence in relationships and it also occurs in same-sex relationships [2]. IPV is also referred to as domestic violence, battering or wife abuse [3]. This study is limited to men's violence against women.

IPV is the most common form of violence to affect women and it occurs in all countries, irrespective of social, economic, cultural or religious system [4]. However, it has been shown to be more common in societies characterised by patriarchal beliefs about the right of the male to exercise power in the family [5], as well as in relationships, where women challenge gender norms [6, 7]. While violence against women is widespread, it is not universal. Anthropologists have documented small-scale societies - such as the Wape of Papua New Guinea - where domestic violence is virtually absent [8]. 
According to World Report on Violence and Health (2002) women often face the greatest risk for being violated at home and in familiar settings [4]. In the same report it is stated that almost half the women who die due to homicide are killed by their current or former husbands or boyfriends. In some countries it can be as high as $70 \%$. While exact numbers are hard to know due to lack of reporting, available data suggest that nearly one in four women will experience sexual violence by an intimate partner in their lifetime [4]. Most victims of physical aggression are subjected to multiple acts of violence over extended periods of time. A third, to over half of these cases are accompanied by sexual violence [4]. Physical violence is always accompanied by psychological violence. World Report on Violence and Health (2002) tells that psychological violence is the most common single form of violence in family and intimate partner violence.

In order to better understand why a male person exercises violence against a close person such as the wife or partner an "ecological framework" can be used to understand the interplay of personal, situational, and socio-cultural factors that combine to cause abuse [9]. Those various factors can be seen as different layers in society interacting with each other. One layer represents the biological and personal history that each individual brings to his or her behaviour in relationships. Another layer represents the immediate context in which abuse takes place, frequently the family or other intimate or acquaintance relationship. A third layer represents the institutions and social structures, both formal and informal, in which relationships are embedded in neighbourhoods, the workplace, social networks and peer groups. The fourth, outermost circle is the economic and social environment, including cultural norms. A wide range of studies agree on several factors at each of these levels that increase the likelihood that a man will abuse his partner [9].

According to WHO [4] evidence from around the world suggests that violence can be prevented by a variety of measures aimed at individual, family and community levels. As a complement to reduce violence against women by legislation, the World Report on Violence and Health, [4] promotes a public health understanding of the complex social, psychological, economic and community underpinnings of violence. Some recent research suggests that biological and other individual factors may explain some of the predisposition to aggression [4]. According to Heise [9], these factors more often interact with family, community, cultural and other external factors and thus create a situation where violence is likely to occur. Understanding these situations and these causes create opportunities to intervene before violent acts occur and provide policymakers with a variety of concrete options to prevent violence [9].

\section{Cultural implication on intimate partner violence}

Challenging violence against women issue actually challenges the various cultural and traditional values men and women hold in different parts of the world. This is a reality particularly among men who are accustomed being considered superior in the hierarchical structure of their own society. Making the issue public and promoting awareness of the issue openly challenges their power not only in society, but also in 
their own families. When considering cultural implications of the women abuse issue, one has to go back to traditional philosophy, which sets the rules about male-female relationships in any culture. Thus, I believe that we have to look into the roots of why men batter.

Cultural and traditional values around the world support male supremacy and dominance over women, and male violence against women in the forms of physical, emotional, and sexual abuse can be justified based on what appear to be culturally acceptable "reasons." Even in women's own ideology and perception they had never viewed themselves as valuable individuals who are equal to men $[10,11]$. This fact is also visible in the findings of this study.

In all societies there are cultural institutions, beliefs, and practices that undermine women's autonomy and contribute to gender-based violence. In recent years, for example, dowry has become an expected part of the marriage transaction in some countries, with future husbands demanding ever-increasing dowry both before and after marriage. Dowry demands can escalate into harassment, threats, and abuse; in extreme cases the woman is killed or driven to suicide, freeing the husband to pursue another marriage and dowry $[10,11]$.

Elsewhere, husbands are expected to pay "bridewealth" to compensate the bride's family for the loss of labour in her natal home. In parts of Africa and Asia this exchange has likewise become commercialized, with inflated bridewealth leaving many men with the impression that they have "purchased" a wife. In a recent survey in the Eastern Cape Province of South Africa, 82\% of women said it is culturally accepted that, if a man pays lobola (bridewealth) for his wife, it means that he owns her. Some $72 \%$ of women themselves agreed with this statement [12].

Cultural attitudes toward female chastity and male honour also serve to justify violence against women and to exacerbate its consequences. In parts of Latin American and the Near East, a man's honour is often linked to the sexual "purity" of the women in his family. If a woman is "defiled" sexually, either through rape or by engaging voluntarily in sex outside of marriage, she disgraces the family honour. For example, in some Arab societies the only way to "cleanse" the family honour is to kill the "offending" woman or girl. A study of female homicide in Alexandria, Egypt, found that $47 \%$ of all women killed were murdered by a relative after they had been raped [13].

Women at the forefront of the women's human rights movement point out that appeal to culture are often an excuse to justify practices oppressive to women. Sudanese physician Nahid Toubia asks, "Why is it only when women want to bring about change for their own benefit that culture and custom become sacred and unchangeable?” [14]. 


\section{Intimate partner violence, a global Human Rights Issue}

Women worldwide, no matter of class, race, culture, religion, nationality and ethnic origin are at constant risk to become victims of human rights violations by means of intimate partner violence. Today, what women around the world share is their vulnerability to the denial and violation of their fundamental human rights [15].

According to Amnesty international [16] a woman is raped every 6 minutes and a woman is battered every 15 seconds in the USA. Two hundred women in Bangladesh will be horribly disfigured when their spurned husbands or suitors burn them with acid. More than 7,000 women in India will be murdered by their families and in-laws in disputes over dowries. Violence against women is rooted in a global culture of discrimination which denies women equal rights with men and which legitimizes the appropriation of women's bodies for individual gratification or political ends. Every year, violence in the home and the community devastates the lives of millions of women [16].

\section{Women's Human Rights in International Law.}

The Universal Declaration of Human Rights [17] stipulates that human rights apply to all people equally, "without distinction of any kind such as race, color, sex, language or any other status". In the case of women there has been a lack of, or at least limited, compliance to the Declaration of Human Rights. In order to strengthen the legal protection of women additional international declarations and conventions have been launched.

The Convention on the Elimination of All Form of Discrimination against Women (CEDAW), or the International Women's Human Rights Treaty, was adopted by the UN in 1979. [17] CEDAW was the first document to comprehensively address women's rights within political, cultural, economic, social and family spheres.

The 1993 Declaration on the Elimination of Violence against Women (DEVAW) [18] set forth ways in which governments should act to prevent violence and to protect and defend women's rights. DEVAW holds states responsible to exercise due diligence to prevent, investigate and, in accordance with national legislation, punish acts of violence against women, whether those acts are perpetrated by the state or by private persons [18].

\section{Empowerment}

The concept of empowerment was first introduced by Rappaport [19] at the beginning of the $1980^{\text {th }}$ in the field of social psychology. According to Rappaport empowerment means aiming at enhancing the possibilities for people to control their own lives. This message was essentially the same as that included in the definition of Health Promotion in Ottawa in 1986. According to the WHO [20] Health Promotion is the process of 
enabling people to increase control over, and to improve their health. The word "empowerment" derives from the same Latin words as "power" and "freedom". Hence, if power is the ability to predict, control, and participate in one's environment, then empowerment is the process by which individuals and communities are enabled to take such power and act effectively in changing their lives and their environment. In relation to intimate partner violence it is of great importance that woman regain power over their own lives in order to reduce the IPV.

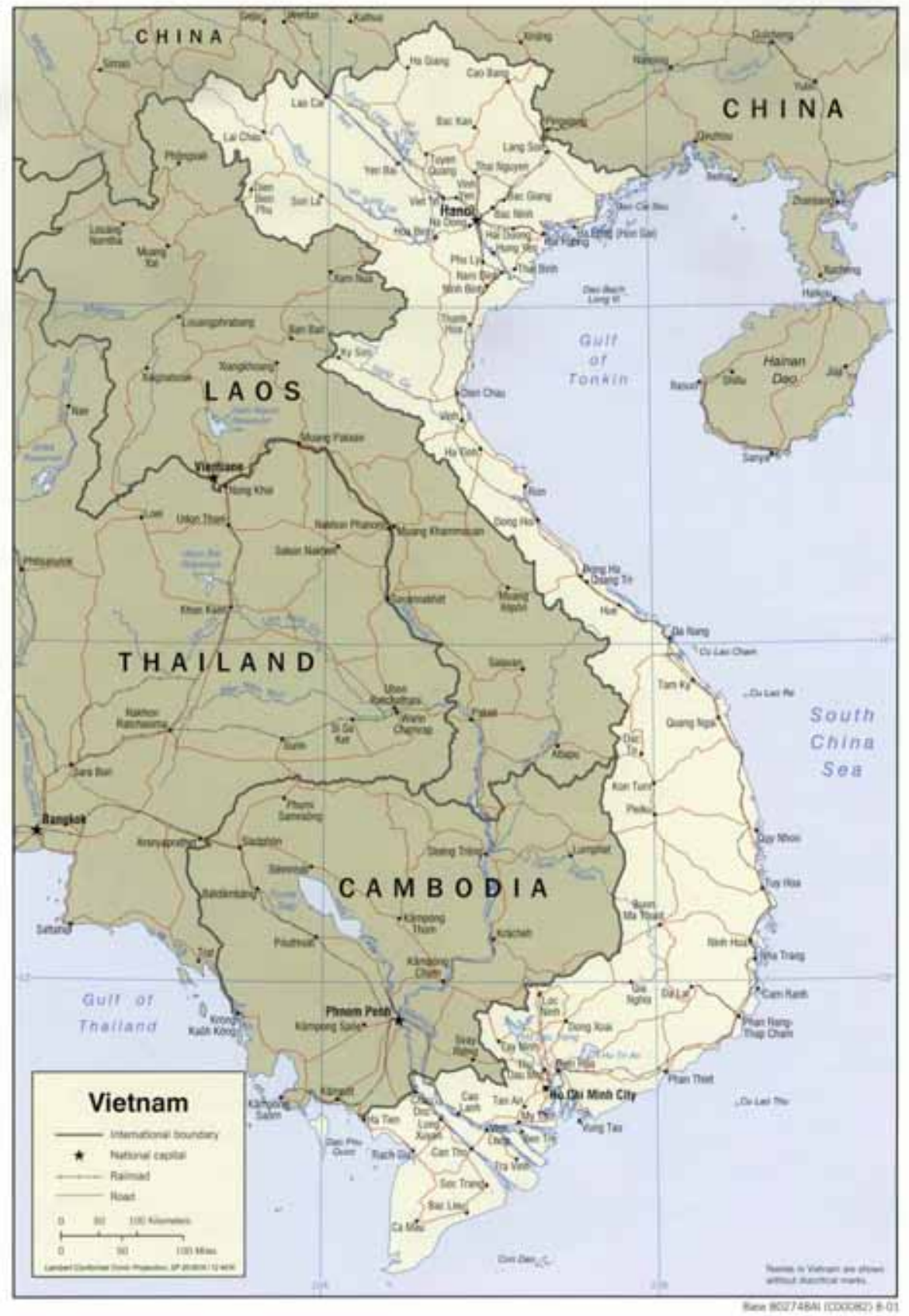




\section{Basic information about Vietnam}

Vietnam, officially the Socialist republic of Vietnam, is located on the eastern coast of the Indochina's Peninsula. Laos and Cambodia border Vietnam in the west, China from the north and the South China Sea in the Southern region. The land area of the country is about 331,000 square kilometres with the see coast stretches over three thousand kilometres along the East Coast of the Indochina's Peninsula. Vietnam is made up of equatorial lowlands, high, temperate plateaus and cooler mountainous areas. Vietnam lies in the inter-tropical zone and the climate varies by geographic location [21].

The estimated population of Vietnam in 1995 was 73,96 million and it is expected to have increased to 91.87 million in the year 2010. During the last decade, 1996 - 2006, the population growth trend is diminishing. This also applies to the infant mortality rate. For the same period the life expectancy at birth is increasing (Table 1).

Table 1. Vietnam: Demographic profile

\begin{tabular}{|c|c|c|c|c|c|}
\hline & 1995 & 2000 & 2005 & 2010 & \\
\hline Population (million) & 73.96 & 80.90 & 86.38 & 91.87 & \\
\hline Males & 36.1 & 40.0 & 42.8 & 45.6 & \\
\hline Females & 37.9 & 40.9 & 43.6 & 46.3 & \\
\hline \multicolumn{6}{|l|}{ Age profile (\% of total population) } \\
\hline $0-14$ & 36.9 & 33.1 & 29.5 & 26.1 & \\
\hline $15-64$ & 58.2 & 61.6 & 65.1 & 68.7 & \\
\hline $65+$ & 4.9 & 5.3 & 5.4 & 5.2 & \\
\hline Median age (years) & 21.4 & 23.1 & 25.0 & 27.1 & \\
\hline Young-age dependency ratio & 0.6 & 0.5 & 0.5 & 0.4 & \\
\hline Old-age dependency ratio & 0.1 & 0.1 & 0.1 & 0.1 & \\
\hline Working age population (million) & 43.0 & 49.8 & 56.2 & 63.1 & \\
\hline Labour force (million) & 34.6 & 40.5 & 44.7 & 48.8 & \\
\hline Period averages & \multicolumn{2}{|c|}{ 1996-00 } & \multicolumn{2}{|c|}{ 2001-05 } & 2006-10 \\
\hline Population growth (\%) & \multicolumn{2}{|l|}{1.6} & \multicolumn{2}{|l|}{1.3} & 1.2 \\
\hline Working-age population growth (\%) & \multicolumn{2}{|l|}{3.0} & \multicolumn{2}{|l|}{2.4} & 2.3 \\
\hline Labour force growth (\%) & \multicolumn{2}{|l|}{3.2} & \multicolumn{2}{|l|}{2.0} & 1.8 \\
\hline Crude birth rate (per 1,000 ) & \multicolumn{2}{|l|}{22.4} & \multicolumn{2}{|c|}{19.5} & 18.5 \\
\hline Crude death rate (per 1,000) & \multicolumn{2}{|l|}{6.8} & \multicolumn{2}{|l|}{6.3} & 6.0 \\
\hline Net migration rate (per 1,000 ) & \multicolumn{2}{|l|}{0.0} & \multicolumn{2}{|l|}{0.0} & 0.0 \\
\hline Total fertility rate (per woman) & \multicolumn{2}{|l|}{2.6} & \multicolumn{2}{|l|}{2.3} & 2.1 \\
\hline $\begin{array}{l}\text { Infant mortality rate } \\
\text { (per } 1.000 \text { live births) }\end{array}$ & \multicolumn{2}{|l|}{38} & \multicolumn{2}{|l|}{32} & 27 \\
\hline \multicolumn{6}{|l|}{ Life expectancy at birth } \\
\hline Males & \multicolumn{2}{|l|}{64.9} & \multicolumn{2}{|c|}{66.9} & 68.4 \\
\hline Females & \multicolumn{2}{|l|}{69.6} & \multicolumn{2}{|c|}{71.6} & 73.1 \\
\hline Total & \multicolumn{2}{|l|}{67.4} & \multicolumn{2}{|c|}{69.4} & 70.9 \\
\hline
\end{tabular}


The Vietnamese society has, as all societies, been shaped through many different religious, philosophical, social and political influences. Confucianism was for many centuries the basis on which the society was built, but with influence also from the main East-Asian religions Taoism and Buddhism. In the $19^{\text {th }}$ century "Western civilisation" was introduced with the French colonisers and in the early $20^{\text {th }}$ century, communism was embraced as an alternative to French rule and traditional feudalism. The renovation policy ("Doi Moi") in the late $20^{\text {th }}$ century and globalisation opened Vietnam to new influences and linked it into the international order of human rights and the free market. Even so, the Vietnamese society and its social structure carry a strong imprint of Confucian thought, which together with Buddhism is again regaining influence, as the influence of communism in daily life is fading (22).

\section{Intimate partner violence in the Vietnamese context}

Present-day Vietnamese society has been described as a combination of old patriarchal traditions, emphasising the subordinate role of women, and modern Communist party ideology advocating equality by law [23, 24]. This has also been expressed as "Vietnamese women today live in two worlds. They do the work of modern women, while they are still expected to behave like their grandmothers" [25]. Current gender roles, responsibilities and relationships continue to be influenced by traditional Confucian doctrine and males generally hold a dominant position within the household [26]. However, in recent years, the country has undergone a rapid transition from a planned economy system to a market economy, where women's rights have been underscored [27]. In 2001, the government launched The National Plan of Action for the Advancement of Women in Vietnam 2001-2005 [28].

Small-scale studies of IPV in Vietnam reveal that it occurs in urban and rural settings and in all social strata [29]. Loi et al. [29] found that district and commune level officials estimated that verbal violence occurred in $20-50 \%$ of families and physical violence in 5-20\%. They further found that all forms of violence occurred less frequently in households where the husband and wife were equal income earners and that verbal abuse was highest in households where the woman was the main income earner.

To prevent trouble in families in Vietnam, "social evils” are to be fought and lifestyle changes promoted. Social evils refer to behaviours, such as the abuse of alcohol and drugs, gambling, having affairs with other women and prostitution. Making "cultural families" is a way to fight social evils and thus reduce or eliminate violence in the family in general and intimate partner violence in particular. "Cultural family" describes a family that has fulfilled certain defined criteria which relate to such behaviour, i.e. no drug or alcohol abuse, having only two children, no divorce, no violence and so on. Families who live up to the set standards receive a certificate issued by local authorities, confirming their immaculate status.

(Hoai Duc, personal communication, 2004). 


\section{THE PRESENT STUDY}

\section{Rationale for the study}

During the past decade, intimate partner violence, referred to as "family violence" or "domestic violence" has become viewed as a global public health problem as well as a violation of human rights. It is of greatest concern to identify the factors behind this phenomenon in order then to find possible ways to prevent those acts.

Questions of the following kind have to be addressed in order to find ways to tackle the problem of IPV:

- What do people think when they hear about family violence?

- What kinds of acts are considered to be violence or maltreatment of women?

- What kinds of situations lead to violence?

- Is this issue related to a particular group of families?

- Is it related to socio-economic conditions or education levels?

- What can we do to make changes to the present situation?

- Are there any organizations to help the couples to settle their problems?

\section{Objectives}

\section{Overall objective}

The overall objective of the study was to contribute to increased knowledge and awareness of violence against women in intimate relationships and thus influence towards a reduction of IPV.

\section{Specific objectives}

The objectives of the study was to describe how people who face partner violence against women, either as volunteers or as professionals in their everyday work, explain violence against women in intimate relationships and their suggestions for preventive activities.

\section{The researcher's background}

In research our interpretations are inevitably influenced by our background, our previous experiences and the discipline we come from. Our reading of data is influenced by our assumptions about the nature of life [30]. In this study, as often is the case in public health research, the researchers involved have their background in different professions representing several disciplines. I, the author of this MPH, am a registered 
nurse teacher with a diploma in public health and university studies in anthropology and sociology. For almost six years I was working in various health related development projects in urban and rural Nepal. At present I uphold position as senior administrative officer at The National Board of Health and Welfare, Stockholm.

The co-authors of the article have different professional and educational background KRC is educated in social science and physiotherapy and is a professor of public health, GK is a MD and associate professor of social medicine and NDV is a MD from Vietnam and a PhD student. Data were collected by two PhD students from Vietnam one MD (TVP) and one educated in economy (NTBT).

\section{METHOD}

\section{A qualitative research approach}

In order to define various perceptions of the phenomenon of violence in intimate relationships, a qualitative research approach was applied for collecting and analysis of data.

According to Malterud [31] qualitative methods are used to obtain knowledge about the characteristics, complexities and interrelationships of phenomena, often specific human matters such as experiences, emotions, beliefs and motives. Qualitative methodology is appropriate when exploring people's perceptions and ideas about a phenomenon and when exploring a new area of study or a field that little is known about [32]. To get the information on how people who face partner violence against women, either as volunteers or as professionals in their everyday work, explain violence against women in intimate relationships and their suggestions for preventive activities, we considered the qualitative research approach to be the best for this study.

\section{The qualitative research interview}

In this study data was collected through focus group interviews. Interviews are particularly useful for getting the story behind a participant's experiences. The interviewer can pursue in-depth information around the topic. In an interview conversation, the researcher listens to what people themselves tell about their lived world, hear them express their views and opinions in their own words, learns about their views on their work situation and family life, their dreams and hopes.

Kvale [32] defines qualitative research interviews as "attempts to understand the world from the subjects' point of view, to unfold the meaning of peoples' experiences, to uncover their lived world prior to scientific explanations." According to Kvale interviews for research or evaluation purposes differ in some important ways from other familiar kinds of interviews or conversations. Unlike conversations in daily life, which are usually reciprocal exchanges, professional interviews involve an interviewer who is in charge of structuring and directing the questioning. In some professional interview situations, such as job interviews or legal interrogations, the power of the questioner is 
much greater than the power of the one being questioned. Therapeutic or clinical interviews are another special kind of professional interview, in which the purpose is to increase understanding and produce change in the person being interviewed. While interviews for research or evaluation purposes may also promote understanding and change, the emphasis is on intellectual understanding rather than on producing personal change [32].

The qualitative research interview seeks to describe and the meaning of central themes in the life world of the subject. The main task in interviewing is to understand the meaning of what the interviewees say [32]. A qualitative research interview seeks to cover both a factual and a meaning level, though it is usually more difficult to interview on a meaning level [32].

There may be different styles of interviewing. Kreuger [33] suggest that the interview follow this pattern: 1 . Opening questions, linked to what the group has as a common base. 2. Introductory questions concerned with the main topic but still not directly related to what the researcher primarily want to know. 3. Questions introducing the keyquestions. 4. Key-questions. 5. Questions to sum up and to make sure nothing has been left out.

The interview process in this study followed close to the pattern Kreuger suggests [33].

\section{Focus group discussions}

Focus group discussions have lately become a method often used in qualitative datacollection in public health research for acquiring information about complex phenomena. According to Dahlgren et al [34] the aim of the focus group discussions is not to quantify comments or opinions but to gain deeper insight and understanding from the participants' perspective. It can be used as an explorative pre-study, the basis for a complete study or a supplement to another primary method, triangulation [35].

A focus group is compiled by people who share common experiences of a phenomenon, as in the present study where various professionals' had experiences of IPV. The participants of a focus group may or may not know each other from before [36]. An ideal seize of the group is 6-10 informants [35]. A moderator guides the group during the discussions. The role of this moderator is to stimulate interaction between the participants. As in the case of all research it is important that the moderator must not have any pre-position of power over the participants.

Focus group discussions have advantages as well as restrictions. An advantage in a focus group discussion is that sensitive topics may be brought up as the group as such make it easier for the individual to open up [33]. In the dynamic group process it is more likely that one will put feelings and thoughts into words. In those situations people tend to be less thoughtful than expected and thus not restrict themselves to share their thoughts [35]. This has both a positive and a negative side. If the individuals in a group discussion do not restrict themselves to talk freely or censor themselves, the richer 
information they probably will contribute with. On the other hand, if the participants are more thoughtful the information may not be as comprehensive as otherwise.

One advantage of focus groups as an interview technique lies in their ability to observe interaction between the participants. Group discussions provide direct information about similarities and differences in the participants' opinions and experiences as opposed to reaching such conclusions from post hoc analyses of separate statements from each interviewee [35]. The ability to give the group control over the direction of the interview is especially useful in exploratory research in which the researcher may not initially even know what questions to ask [35]. When comparing focus group discussions with other interview techniques one must be aware of the dynamic of a group discussion, where one person will inspire the next to a broader and deeper thought and understanding. Thus, if similar questions were addressed in a group discussion and in individual interviews with the same people, the findings may be different.

\section{Study setting}

This study forms part of a larger project on violence against women in northern rural Vietnam. The present study was conducted within the framework of the demographic surveillance site in Bavi District, Ha Tay Province, in northern rural Vietnam. The field site was established in the late 1990s in a collaborative programme between Vietnamese and Swedish researchers and a number of studies of different health-related topics are currently ongoing [37].

In Bavi district, agricultural production and livestock breeding are the main economic activities of the local people (81\%) [37]. Illiteracy is low (0.4\%), but it is considerably higher among women than among men. About $70 \%$ of the adult population has completed primary school, 21\% secondary level, 9\% high school and 0.6\% higher education, but, the higher the educational level, the lower the number of females [38]. The health care system in Bavi district is organised with one district hospital and 32 communal health centres, with one in each commune [39].

\section{Selection of informants}

In all, 40 persons, 20 men and 20 women, participated in five focus-group discussions, conducted in May and June 2002. The informants were strategically selected with respect to gender and occupation, i.e. they were either health-care staff or persons who held positions at district or local community level, and some of them were elected representatives of local reconciliation groups. The selection of informants was made with the support of the deputy-director of the District Health Centre, who is well acquainted with local conditions. About characteristics of the informants and how the groups were composed see Table 2. 
Table 2. Characteristics of the focus-group participants, position and gender and venue for the focus-group discussions.

\begin{tabular}{|c|c|c|}
\hline Position & Male/female & Venue \\
\hline $\begin{array}{l}\text { G1: Commune health workers: } \\
\text { Assistant physicians (6), } \\
\text { village health workers (2) }\end{array}$ & $3 / 5$ & CHS \\
\hline $\begin{array}{l}\text { G2: District health professionals: } \\
\text { Physicians (5), assistant physicians (2), } \\
\text { nurse (1) }\end{array}$ & $4 / 4$ & DHC \\
\hline $\begin{array}{l}\text { G3: District officers: } \\
\text { Representatives from: } \\
\text { farmers' association (1), women's } \\
\text { union (1), youth union (1), inspection } \\
\text { office (1), court institution (1), } \\
\text { propaganda unit (1), health office (1) }\end{array}$ & $4 / 3$ & DHC \\
\hline $\begin{array}{l}\text { G4: Men at community level: } \\
\text { Farmers (5), representatives from: } \\
\text { farmers' association (1), youth union } \\
\text { (1), Commune People’s Committee (2) }\end{array}$ & $9 / 0$ & CHS \\
\hline $\begin{array}{l}\text { G5: Women at community level: } \\
\text { Farmers (5), representatives from: } \\
\text { Commune People's Committee (1), } \\
\text { women's union (1), youth union (1) }\end{array}$ & $0 / 8$ & CHS \\
\hline
\end{tabular}

G: Focus group; CHS: Commune Health Station; DHC: District Health Centre 
Three of the groups had mixed sexes, one group had only males and one only females. The assistant physicians, with two years of medical training at a medical school, all worked at commune health stations (CHS), as did the village health workers. The physicians and the nurse specialised in paediatrics, gynaecology, emergency care and general medicine respectively all worked at the district hospital. The participating district officers were chairpersons or directors of their respective associations. The menonly group and the women-only group consisted of farmers and heads of local associations, while some were members of local reconciliation groups.

\section{Data collection}

Five focus-group discussions were conducted [40]. They were semi-structured, informal in style and lasted for approximately one and a half hours. The moderator of the mixedsex groups (G1-G3) was a male, assisted by a female co-moderator. The moderator and co-moderator of the exclusive male and female focus-group discussions were males and females respectively. The male and female moderators were professionals, pursuing their doctoral studies. Four themes were covered in the focus group discussion: 1. Forms of IPV, 2. Consequences of IPV, 3. Explanations to IPV and 4.Suggestions for preventive activities. The guiding questions were of a comprehensive character, such as: In your opinion, what are the forms of violence and maltreatment on women? What in your view are the consequences of intimate partner violence? In your opinion, what are the possible explanations to violence between husband and wife? What kind of situation leads to violence? As you see it, how do husband and wife settle their problems? What do you think could be done to reduce this violence? The informants were asked to give examples.

\section{Analysis}

The first two themes, forms and consequences of intimate partner violence, are analysed elsewhere [1]. Thus this MPH with the enclosed article focus on the two themes; I. Explanations to why violence against women in intimate relationships occurs and II. Suggestions for preventive activities. The discussions were tape-recorded and transcribed verbatim in Vietnamese and then translated into English. The analyses followed the procedure for qualitative thematic content analysis as described by Burnard [41]. Content analysis focuses either on describing the visible, obvious components of the text, referred to as the 'manifest content', or on interpreting the underlying meaning of the text, which gives the 'latent content' [42]. In this study, the analysis focused on the manifest content.

RJ and NDV had the main responsibility for the analysis. The interview transcripts were read through several times in order to become immersed in the data. Thereafter the interviews were coded by identifying open codes. Similar codes were grouped into subcategories which in turn formed categories corresponding to the two main themes I. Explanations to why violence against women in intimate relationships occurs and 
II. Suggestions for preventive activities. The results from the initial independent analysis were then compared and discussed in between all the authors throughout all stages of analysis.

\section{Validity}

According to Kvale [32] validation in connection to qualitative research is a process of control and questioning that begins where the relevant research questions are defined, and ends at the writing of the report of the study. Thus, the validation consists of this on going questioning throughout the whole research process.

Validation takes place in seven steps as described by Kvale [32]:

1. Theme making. The validity of the study is depending on relevant theory and its link to the research questions.

2. Planning. The validity of the knowledge produced depends on the degree of relevant planning and what methods used. From an ethic point of view the planning of the research become valid if it produces knowledge to the people with a minimum of negative consequences.

3. Interview. The validity in this case has to do with trustworthiness to the reports of the researcher and the quality of the interview e.g. to reconfirm the information reviewed.

4. Transcript. The question of what is a valid translation, from verbal language to written text, depends on the form of the language used for the transcript.

5. Analyse. This has to do with the validity of the questions used in the interview and if the logic of the interpretation is solid.

6. Validation. This has to do with evaluation of the forms of validation and its relevance to a specific study, its applicability to procedures of validation and the decision of what group is suitable opponent in a dialogue about the validity.

7. Report. The question here is whether a report is a valid description of the main results of a study and the role the reader will play in connection with the validation of the result.

The validation of this study has been done in accordance to Kvale's 'seven steps'. The project was planned thoroughly during a period of time. In the preparation part of the study an inventory was done in relation to intimate partner violence, e.g. what previous studies had been done and with what approaches. Those involved in the interviewing part had special training in interview technique before entering the project. To secure the validity of the translation of the focus group interviews, an independent Vietnamese person, proficient in English, read all the selected quotations from the original Vietnamese transcript and re-translated them into English. The thematic questions were tested in a group of students, coming from developing countries, before starting the actual research interviews. The findings that emerged in this study were discussed continuously between all involved researchers to secure validity. The researchers involved in the project were from both Vietnam and Sweden. The results have also been discussed in a research course peer review. To further test the intersubjective agreement, a methodology used within phenomenography [43, 44] was 
applied; the themes, the categories and the selected quotations were presented separately to an independent co-examiner, who was given the task of matching the quotations to the themes and the categories. Almost a full level of agreement was found between the researchers and the co-examiner. The quotations given here are intended to facilitate the reader's evaluation of the validity of the results. A paper has been written and sent to an international journal with a system of referee. In addition the results have been presented at various conferences.

The findings were reported back to the informants one year after the focus group discussion at a formal meeting in Bavi. Twenty-eight of the forty informants participated and they confirmed the findings.

\section{ETHICAL CONSIDERATIONS}

This study was part of a bigger project, a bilateral collaborative programme between Vietnamese and Swedish researchers. When there is a collaborative programme between different countries it is of great importance that before starting the study ethic committees in both countries concerned give approval to the study. Before starting the present study the Ministry of Health in Vietnam, the Local Health Authority in Vietnam and the Research Ethics Committee at Göteborg University approved the study. The Guideline on Ethics and Safety for Violence Research, issued by the WHO in 1999 [45] was followed as well as the principles of Helsinki Declaration [46].

The fundamental document regarding ethical guidelines for human research is the Declaration of Helsinki, originally adopted by the World Medical Assembly in 1964, with later revisions at regular intervals. The Declaration of Helsinki includes several important principles. Human research ethics assume some consensus on four basic principals for conduct: The Principle of Autonomy implies that all persons have a right to decide about their actions and resources and that society has a moral duty to respect this right. The Principle of Nonmaleficence is referred to as the principle to do no harm. The Principle of beneficence refers to a moral obligation to do as much good as possible and is not limited to mercy, kindness or charity. The Principle of Justice requires that human beings be treated equally unless there is a strong ethical justification for treating them differently. These principles comprise the foundation of all regulations or guidelines governing human research ethics and transcend all geographic, cultural, economic, legal, and political boundaries and are extensively discussed by Beauchamp and Childress [47].

When it comes to ethical considerations, public health research differs from biomedical and clinical research in several important respects. Its focus is mainly on the distribution, determinants and consequences of health and disease patterns in populations rather than on individuals or patient groups. The public health research has a clear political aspect in the way we choose which health problems to study and the aspects of the problem that we decide to focus on. The political and ethical considerations in these choices are to a large extent based on our evaluation of what a fair and just society should look like in terms of health [34]. If public health research in 
general is considered to have a clear political aspect as well as ethical implications it applies most definitely in the case of this study on intimate partner violence.

Dahlgren et al [34] discuss ethical considerations in relation to the use of qualitative methodology in public health research. Qualitative methodology is often regarded as less threatening on an individual level, because of the implied interaction between informants and researchers and the interest in viewing or understanding the "real world" of the informants. On a societal level it is also often argued that qualitative methodology empowers people through their active participation in the research process. However, even if this is true, there are ethical considerations to be taken in all research, some from a more political and ethical angle and some from a more individual point of view [34].

In contrast to the idea that qualitative methodology can be seen as less threatening to the individual the qualitative approach may be more threatening to the individual than when for example one give the answers in a questionnaire. It is of great importance to ensure confidentiality to the participants of a focus group discussion and that what has been said in the discussion must not be talked about outside the group. From an ethical point of view it is also important to ensure the participants that the results will be presented in such a way that no individual will be recognised.

The topic of this study was of a sensitive kind and there was a possibility that someone amongst the participants had experienced IPV herself and thus having emotional reactions.

In order to be prepared for such an event that issue had been discussed within the research group before starting the focus group discussion. In addition, professional counsellors had been contacted in advance to be prepared to take care of any participant that would need such help in connection to the discussions.

Ethical considerations must be taken into account when doing research in a foreign country. It requires sensitiveness and awareness of the fact that an expatriate researcher is a guest in the place where the research activities takes place. Thus the attitude towards the counterpart has to be in accordance to that fact. In order not to leave out the cultural perspective in any part of the study an expatriate researcher should always involve local counter partners. This also has ethical implications. In this study the entire research process was done in collaboration between Vietnamese and Swedish researchers working closely together. 


\section{FINDINGS}

A comprehensive presentation of the findings is presented in the attached article and thus only a summary of the findings is given here, together with a synthesis of the results. The article is currently under review for later publication.

The findings relate to the two main themes covered in the interviews, explanations to why violence against women in intimate relationships occurs and suggestions for preventive activities.

The themes are described by four and three categories respectively, with subcategories and these are summarised in Table 3.

\section{Explanations to why violence against women in intimate relationships occurs}

Intimate partner violence was seen by the informants as a complex interplay between many factors mirroring different levels of societal organisation. The violence was described as linked to individual factors, partner and family relationships, local community factors and socio-cultural norms and practices.

\section{Suggestions for preventive activities}

The need for improved knowledge among rural people on gender equality issues was underlined and some of the informants suggested mediation as a successful way of settling disputes in the family. The suggestions given for preventive activities were also related to different levels of societal organisation.

Participants of this study, women and men, professionals and lay people at local level in a rural district in Vietnam were well informed about violence against women in the family. However, they stated that this problem is not discussed openly in the community and women who are subjected to violence keep silent and avoid seeking help in order not to reveal what is happening in the family. A hesitation to intervene was also found among some of the informants, the medical doctors, while all the others were eager to discuss activities but mainly those that were already in place. One striking finding was that the informants were hardly able to suggest preventive activities directed at individuals but focused mainly on government policies and strategies. 
Table 3. Explanations given to IPV and suggestions for interventions. Themes, categories, sub-categories and a selection of codes

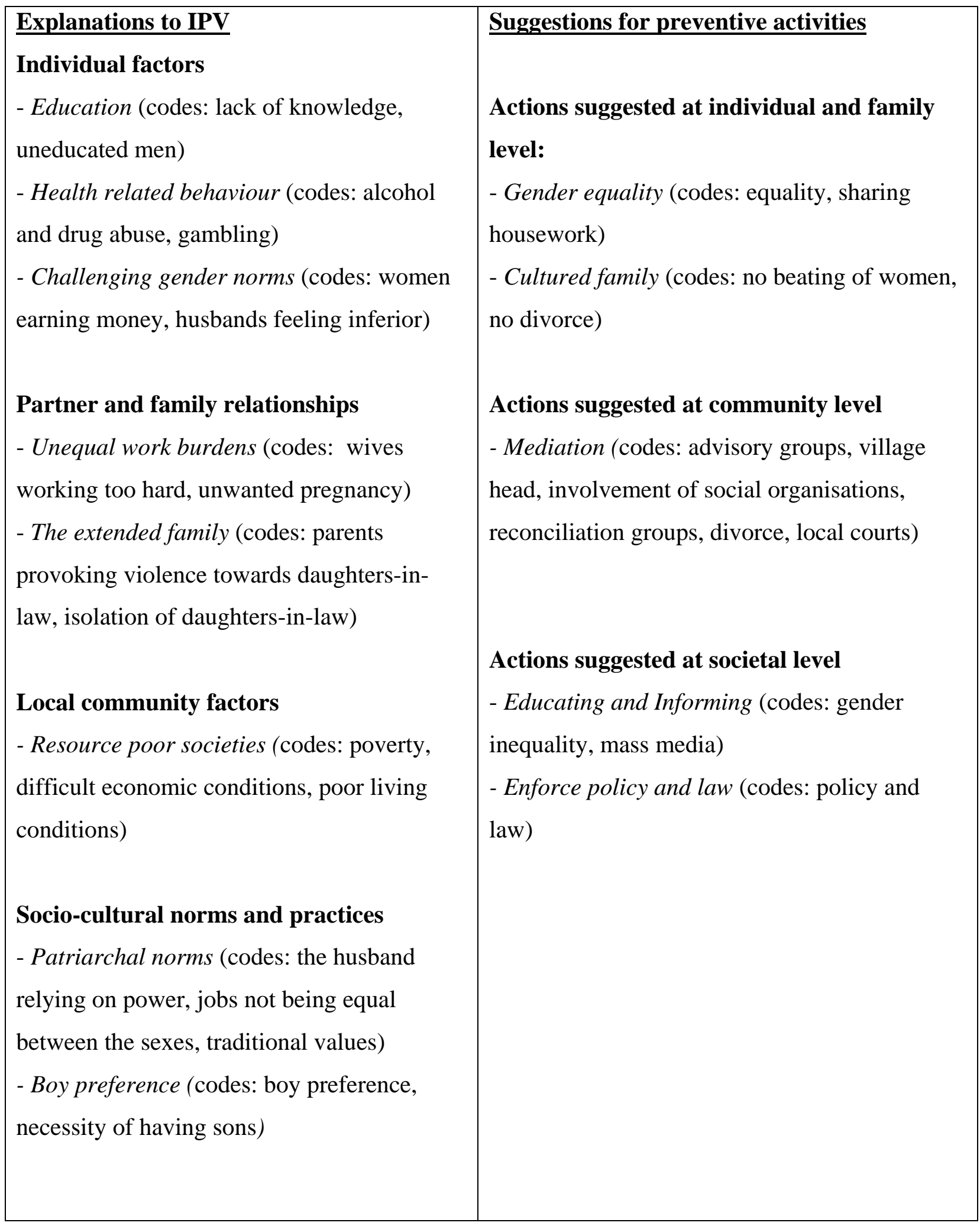




\section{Synthesis:}

I. The informants' explanations to why violence against women in intimate relationships occur

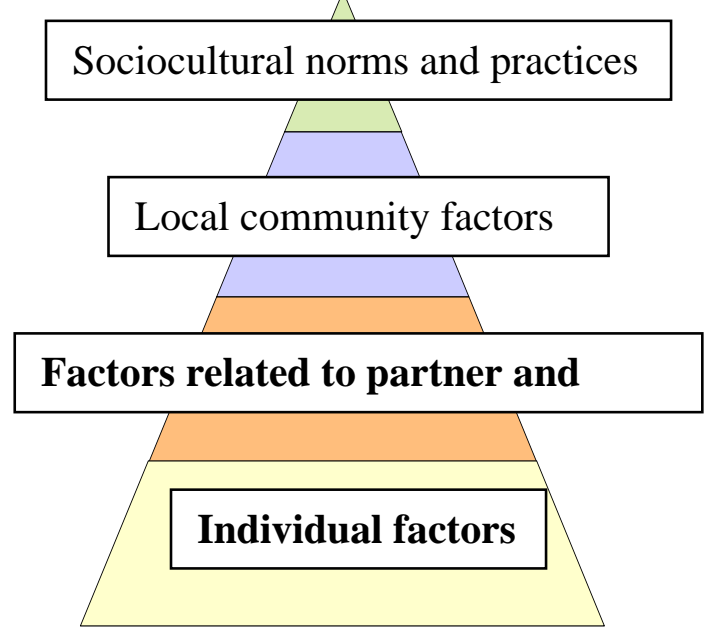

Looking at what explanations the informants had to violence against women in intimate relationships it was shown that they focused mainly on factors related to the individual and to factors related to partner and family.

II. The informants' suggestions for preventive activities

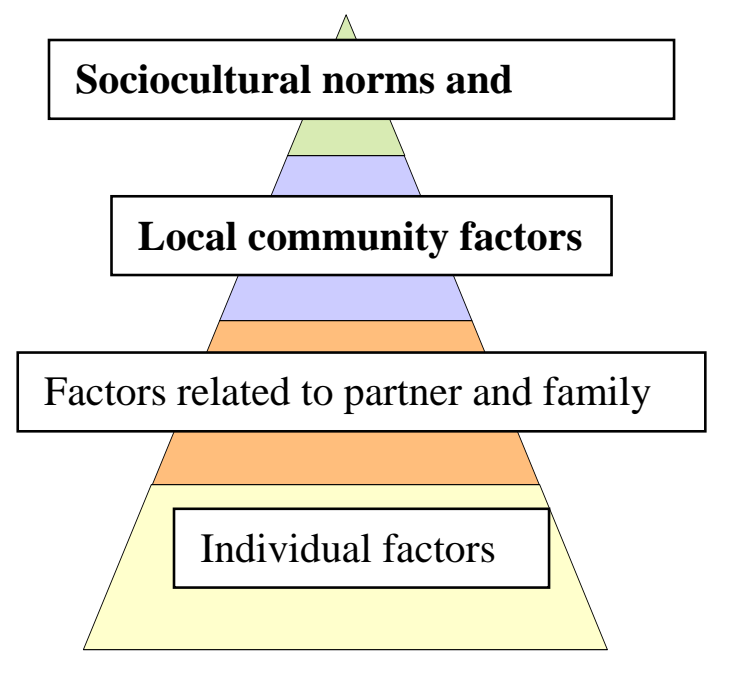

Regarding suggestions for preventive activities the informants did not focus on the individual or family level. They considered the deep rooted gender based ideas on power being difficult to do something about as an individual. It may also have to do with the political system in which they live. Instead they suggest interventions on societal level e.g. improvements of policies and law.

III. Our suggestion for preventive activities 


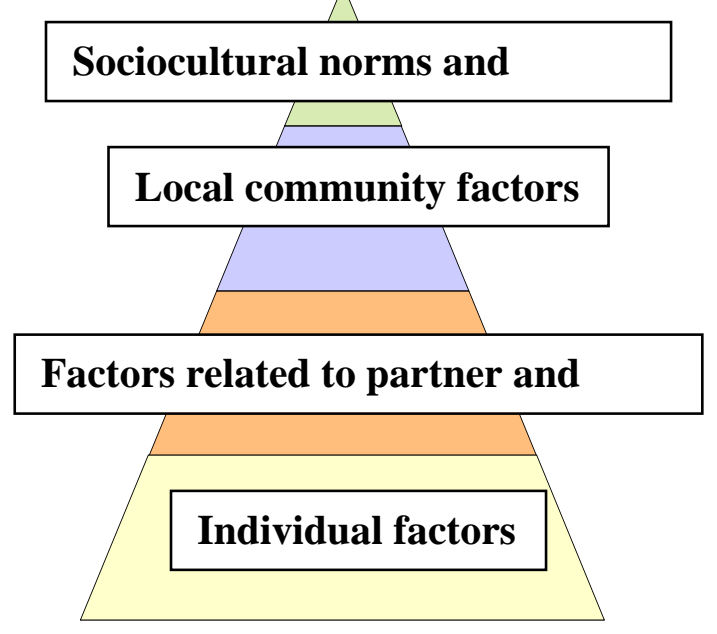

We have in our analysis in relation to preventive actions enforced the need for intersectoral and multidisciplinary actions. We also suggest that the women have to be strengthened and empowered.

\section{DISCUSSION}

This study shows that the informants of this study; professionals, such as health-care staff and district officers, as well as trusted citizens, acknowledged violence against women as a multifaceted phenomenon grounded in the interplay between individual, family, local community and socio-cultural norms and practices.

Men's level of education and their health damaging behaviour were by informants considered factors that perpetuate violence in the family. Women's low status in the extended family was underpinned by women's extremely high work burden, and by the fact that also family members other than the husband could use violence towards her. Further, for a woman to challenge traditional gender norms, such as earning a higher salary than the husband or being in a higher position, were considered as putting her at risk of violence. This finding is in line with what has been found in other studies in that status inconsistency in the family as well as in the local society has been found to be a greater risk factor of violence than the absolute income [7].

The strong patriarchal society and as a part of this, the boy preference idea (the strong wish to get a baby son instead of a daughter) were other factors considered by the informants to contribute to violence against women within the family sphere.

The informants' way of explaining violence against women in intimate relationships corresponds well to the integrated ecological framework for understanding the origins of gender based violence as described by Heise [9]. This model describes four levels of analysis: personal history factors; the immediate context in which the abuse occurs; formal institutions and structures such as workplace, social networks and neighbourhoods and, finally, the economic and social environment and cultural norms in the particular society.

However, even though it is possible to conceptualise and sort explanations into different levels of analysis, we found in our study that behind all of them lie the culturally constructed conceptions about the proper roles of men and women mirroring women's power disadvantage. The informants stressed that, as long as society is permeated by patriarchal thinking and gender inequality is accepted, the violence will continue. 
However, male dominance in society is not a sufficient cause to explain violence in the family. A valid theory should be able to explain why individual men become violent, while others do not. For this purpose, the ecological framework [9] serves as a useful tool for analysis and it also suggests areas for prevention.

When attempting to delineate gender differences in opinions between the informants, one interesting finding was that the female participants in particular stressed the importance of women's behaviour to avoid violence in the family. This indicates that, although the female informants were critical of the gender power asymmetry, they also strove to uphold traditional values. This in turn possibly reflects the rapid transition that Vietnam has undergone in recent years and the process which has resulted in women making their way between two different ideological approaches.

The suggested preventive activities also referred to different levels in society, the individual/family, the community and the societal level. These suggestions were however, mainly grounded in existing bodies or functions at local level. Some were specific to Vietnamese conditions, such as building 'cultural families', receiving support from local Women's Union staff and relying on reconciliation groups and local courts to reconcile couples. Cultural families are also mentioned in the National Plan of Action for the Advancement of Women in Vietnam as a means of improving women's equal rights and benefits in the family context [28].

The medical staff felt that they were failing in preventing violence against women in the family and were reluctant to interfere in domestic matters. This is also well documented from most other countries and reflects shortcomings among professionals due to inadequate training and lack of experience in diagnosing, treating and preventing such cases [48].

\section{Methodological considerations}

Focus-group discussions does not aim to quantify comments or opinions but to gain deeper insight and understanding from the participants' perspective [34]. It is possible to reach a large number of informants in a short period of time and to reach a higher level of understanding among the participants as they influence each other through discussing.

According to Morgan [35] focus groups are frequently conducted with purposively selected samples in which the participants are recruited from a limited number of sources (often only one). Random sampling is seldom of use in selecting participants for focus groups [35].

There are different opinions on whether it is good or bad that the participants in a focus group know each other. According to Kreuger [33] the use of focus group is not suitable when the topic is sensitive or where secrecy can not be guaranteed. Further, Kreuger argues that the moderator and the participants must not know each other since the participants then may be influenced by the opinions of the moderator. 
The selection of participants to this study was done by the deputy director of District Health Centre. In this way we could trust that the selected participants would know sufficiently enough of the topic concerned as well as they would be considered to have the ability to talk and share their view openly in a group. Even if everyone was said to participate on his or her own will one cannot know for sure if someone felt a pressure to participate. The participants in a focus group would most probably fear to talk freely and honest about sensitive topics, such as violence against women, if they do not know each other well. It may though for some individuals be the opposite, that not knowing the others gives a greater feeling of freedom to share personal opinions on sensitive topics. However, one have to consider the possible risk of obtaining only "politicallycorrect opinions" when gathering people who may not be familiar with each other. In order to increase secure confidentiality or anonymity in relation to the participant's answers one could consider whether individual interviews would have met this particular need in a better way. Even though this can not be ruled out in our study, we noticed that the subject of violence against women was of such great interest and challenged the participants to really give their opinions and to share viewpoints beyond politically-correct statements. Furthermore, the interviews were held in Vietnamese, which enabled all the participants to express their views in a precise way.

According to Morgan [35] the comparative advantage of focus groups as an interview technique lies in their ability to observe interaction on a topic. Group discussions provide direct evidence about similarities and differences in the participants' opinions and experiences as opposed to reaching such conclusions from post hoc analyses of separate statements from each interviewee. This reliance on group interaction, however, also means that individual interviews have clear advantages over focus groups with regard to (a) the amount of control that the interviewer has and (b) the greater amount of information that each informant has time to share.

Issues of control over the interview, however, can sometimes favour focus groups. In particular, group discussions make it easier to conduct "less structured interviews" in which there is no preconstructed interview guideline or questionnaire. This ability to give the group control over the direction of the interview is especially useful in exploratory research in which the researcher may not initially even know what question to ask [35].

\section{Generalizations of the results}

The findings in this study cannot be generalised to a broader population, but they may serve as an 'eye-opener' that helps to generate new strategies for ways of combating violence against women in intimate relationships.

\section{Conclusions and recommendations for future work against IPV}

This study shows that behind all of the explanations to intimate partner violence laid the culturally constructed messages about the proper roles of men and women mirroring gender inequality and women's power disadvantage. A hesitation to intervene was found among some of the informants, the medical doctors, while all the others were 
eager to discuss activities but mainly those they were already undertaking and it seems the local level require further support to better handle this problem.

It is through education, awareness raising, advocacy, counselling, investigating and prosecuting offenders and by giving support to women who dare bring their own experiences into the open that violence can be acted upon.

Government and ministries need to speak out clearly against this violation of women's human rights and give support to organisations at regional and local level to improve the handling of this problem. The mass media have a role to play, through radio broadcasts and newspaper articles, which also need to address the young people.

The National Plan of Action for the Advancement of Women in Vietnam 2001-2010 [28] spells out objectives with indicators for attaining a higher level of gender equality and for ending violence against women and a Domestic violence prevention and control law will be submitted to the National Assembly in 2007. However, we found that the local level needs further support to assume this responsibility.

For many abused women, contact with primary care providers may be the only opportunity for effective intervention, as health-care staff is obliged to observe professional secrecy. Asking about violence can lead to earlier interventions or can help women to leave abusive relationships, provided the staff are supportive of their patients' emotional needs. Intersectoral collaboration at local level, between the health sector and other bodies and with community leaders as spokesmen, would help to improve openness and reduce society's tolerance of violence against women. 


\section{ACKNOWLEDGEMENTS}

I want to express my sincere gratitude and appreciation to my supervisors, professor Karin Ringsberg, The Nordic School of Public Health, Göteborg and associate professor Gunilla Krantz, The Sahlgrenska Academy, Göteborg University. Without their enthusiasm, encouragements and not least the many good advices, this work would not have been accomplished. I especially want to thank Professor Karin Ringsberg for her patience in her ongoing supervision work and for sharing her deep knowledge in the methodology part. Likewise I have benefited tremendously from associate professor Gunilla Krantz's comprehensive knowledge on the subject of this study, intimate partner violence.

I also want to thank PhD student, Nguyen Dang Vung for his kind cooperation in this work as well for his friendly hospitality during my visit to Vietnam. Finally, I want to express my gratitude toward $\mathrm{PhD}$ student T.Van Phuong and PhD student N.Thi Bich Thuan who conducted the focus group discussions. 


\section{References:}

[1] Krantz G, Van Phuong T, Larsson V, Thi Bich Thuan N, Ringsberg KC. Intimate partner violence: forms, consequences and preparedness to act as perceived by healthcare staff and district and community leaders in a rural district in northern Vietnam. Public Health 2005;119(11):1048-55

[2] Heise L, Ellsberg M, Gottemoeller M. Ending violence against women. Population Reports Series L, No 11, Volume XXVII, Number 4. Baltimore: Johns Hopkins University School of Public Health, Population Information Programme;1999. p. 3-8.

[3] Krantz G, Garcia-Moreno C. Glossary on violence against women. Journal of Epidemiology and Community Health 2005; 59:818-821.

[4] World Report on Violence and Health. Geneva, World Health Organisation; 2002.

[5] Yllo K, Straus M A. Patriarchy and violence against wives: the impact of structural and normative factors. In: Straus M A, Gelles R J (eds). Physical violence in American families: risk factors and adaptations to violence in 8145 families. New Brunswick, NJ: Transaction Publisher 1990. p. 383-399.

[6] Hamberger L K, Lohr J M, Bonge D, Tolin D F. An empirical classification of motivations for domestic violence. Violence against women 1997; 3: 401-423.

[7] Jewkes R. Intimate partner violence: causes and prevention. The Lancet 2002; 359:1423-1429.

[8] Counts DA, Brown J, Campbell J. Sanctions and sanctuary: cultural perspective on the beating of wifes. Boulder, Colorado: Westview Press, 1992.

[9] Heise L. Violence against women. An integrated, ecological framework. Violence against women 1998; 4 (3): 262-290.

[10] Rao V. Wife-beating in rural South India: A qualitative and econometric analysis. Social Science and Medicine 44(8): 1169-1179. 1997.

[11] Schuler S.R, Hashemi S.M, Riley A.P, and Akhter S. Credit programs, patriarchy and men's violence against women in rural Bangladesh. Social Science and Medicine 43(12): 1729-1742. 1996.

[12] Jewkes R, Penn-Kekana L, Levin J, Ratsaka M, and Schrieber M. He must give me money, he mustn`t beat me: Violence against women in three South African Provinces. Pretoria, South Africa, Medical Research Council, 1999. 29 p. 
[13] Graitcer P. and Youssef Z. Injury in Egypt: An analysis of injuries as a health problem. Washington, D.C. and Cairo, U.S. Agency for International Development and Ministry of Health, 1993. 119 p.

[14] Heise L, Moore K, and Toubia, N. Sexual coercion and women's reproductive health: A focus on research. New York, Population Council, 1995. 59 p.

[15] http://www.amnestyusa.org/women

[16] Amnesty international. Broken Bodies, Shattered Minds: Torture and Ill Treatment of Women, Amnesty International, 2001

[17] http://www.un.org/Overview/rights.html

[18] The 1993 Declaration on the Elimination of Violence Against Women (DEVAW) Homepage: http://www.un.org/womenwatch/daw/

[19] Rappaport J. In praise of paradox. American journal of community psychology 1981; 9 (1):1-25.

[20] WHO 'A discussion document on the concept and principles of health promotion'. Health Promotion 1986a; 1: 73-76.

[21] Giang K B. Assesing health problems. Self reported illness, mental distress and alcohol problems in a rural district in Vietnam. Doctoral dissertation. Karolinska institutet; 2006.

[22] Rubensson, B. Working Children's experiences and their right to health and wellbeing. Doctoral dissertation. Karolinska institutet; 2005.

[23] Johansson A. Dreams and dilemmas: women and family planning in rural Vietnam. Doctoral dissertation. Stockholm, Karolinska Institutet; 1998.

[24] Thinh H B. Vietnamese laws and domestic violence. Reports in the seminar on domestic violence against women and the role of mass media for women's development. Hanoi, Research Centre for Gender, Family and Environment in Development (CGFED); 2001.

[25] Franklin B A K. Expanding horizons; Changing gender roles in Vietnam. A report on the audience research \& analysis and the media campaign for gender. Hanoi: National committee for the advancement of women in Vietnam, project VIE/96/011; 2000. http://www.ubqgphunu.gov.vn/english/eh/expanding.html

[26] Rydstrom H. Encountering "hot” anger. Domestic violence in contemporary Vietnam. Violence Against Women 2003; 9: 676-697.

[27] Johansson E, Long N H, Diwan V K, Winkvist A. Attitudes to compliance with tuberculosis treatment among women and men in Vietnam. The International Journal of Tuberculosis and Lung Disease 1999; 3 (10): 862-868.

[28] Government of Vietnam. Hanoi, National plan of action for the advancement of women in Vietnam 2001-2005; 2001. http://www.ubqgphunu.gov.vn/English/

[29] Loi V M, Huy V T, Minh, N H, Clement J. Gender-based violence: The case of Vietnam. Hanoi: Report from the Institute of Sociology; 2000.

[30] Strauss A, Corbin J. Basics of qualitative research. Newbury Park: Sage Publications, 1990.

[31] Malterud K. Shared Understanding of the qualitative Research Process. Guidelines for the Medical Researcher. 1993. Family practice. 10 (2) 201-206

[32] Kvale S. Interviews. An introduction to Qualitative Research Interviewing. Thousand Oaks CA: Sage Publications, 1996.

[33] Krueger R.A, Focus groups: A practical guide for applied research ( $\left.2^{\text {nd }} \mathrm{ed}.\right)$ Thousand Oaks, CA: Sage. 1994. 
[34] Dahlgen L, Emmelin M, Winkvist A. Qualitative Methodology for International Public Health.Umeå: Umeå International School of Public Health; 2004.

[35] Morgan D. L, Focus groups as qualitative research, Qualitative Research Methods Series, Volume 16, Second Edition, Sage Publications, 1997

[36] Morgan D L, Krueger R A. When to use focus groups and why. In D L Morgan (Ed.), Successful focus groups: Advancing the state of the art (pp 3-19). Newbury Park, CA: Sage. 1993.

[37] Chuc NTK, Diwan V, FilaBavi A. A demographic surveillance site, an epidemiological field laboratory in Vietnam. Scand J Pub Health 2003; 31(Suppl.62):3-7.

[38] Que TT, T.SY, Uyen VN, Bang NT. Gender basic concepts and gender issues in Vietnam. Hanoi: Centre for gender, environment and sustainable development studies; 1999.

[39] Hoa NP, Diwan VK, Thorson AE. Diagnosis and treatment of pulmonary tuberculosis at basic health care facilities in rural Vietnam: a survey of knowledge and reported practices among health staff. Health Policy 2005; 72(1):1-8.

[40] Barbour R S, Kitzinger J. Developing focus group research. Politics, theory and practice. London: Sage Publications; 2000.

[41] Burnard P. A method of analysing interview transcripts in qualitative research. Nurse Education Today 1991; 11:461-466.

[42] Graneheim U H, Lundman B. Qualitative content analysis in nursing research: concepts, procedures and measures to achieve trustworthiness. Nurse Education Today 2004; 24: 105-112.

[43] Lepp M, Ringsberg K C. Phenomenography - a qualitative research approach. In: Hallberg L M (ed). Qualitative methods in public health research - Theoretical foundations and practical examples. Lund: Studentlitteratur; 2002. p. 105-129.

[44] Sjöstöm B, Dahlgren, L O Applying phenomenography in nursing research. Journal of Advanced Nursing 2002; 40(3): 339-345.

[45] Guidelines on ethics and safety for violence research. Geneva: World Health Organisation; 1999.

[46] World medical association declaration of Helsinki. Ethical Principles for Medical Research Involving Human Subjects. Adopted by the 18th WMA General Assembly, Helsinki, Finland, June 1964.

[47] Beauchamp T L, Childress J F. Principles of Biomedical Ethics. New York: Oxford university press. 1989

[48] Garcia-Moreno C. Dilemmas and opportunities for an appropriate health-service response to violence against women. Lancet 2002; 359:1509-1514. 
Nordic School of Public Health • Box 12133 • SE-402 42 Göteborg

Visiting address: Nya Varvet • Building 25 • Phone: +46 (0)31 693900 • Fax: +46 (0)31 691777

E-mail:administration@nhv.se•www.nhv.se 